pp 1146-1169. (C) The Author(s) 2020. Published by Cambridge University Press on behalf of Royal Aeronautical Society

doi:10.1017/aer.2020.19

\title{
Comparison and analyses of a variable span-morphing of the tapered wing with a varying sweep angle
}

\author{
M. Elelwi, M.A. Kuitche, R.M. Botez and T.M. Dao \\ ruxandra.botez@etsmtl.ca \\ ETS, Laboratory of Active Controls \\ Avionics and AeroServoElasticity LARCASE \\ 1100 Notre Dame West \\ Montreal, Quebec \\ Canada
}

\section{ABSTRACT}

This work presents a comparative study of design and development, in addition, of analyses of variable span morphing of the tapered wing (VSMTW) for the unmanned aerial vehicle (UAV). The proposed concept consists in the sliding of the inner section into the fixed part along the wing with varying the angle of the inner section inside the fixed part (parallel with the leading edge and the moving-wing axis is coincident to the fixed-wing axis) within two configurations. The wing design is based on a NACA 4412 aerofoil with the root chord of $0.675 \mathrm{~m}$ and the tip chord of $0.367 \mathrm{~m}$ for the fixed segment and $0.320 \mathrm{~m}$ for the moving segment. Morphing wing analysis occurs at three selected locations that have been specified for extending and modifying span length by $(25 \%, 50 \%$, and $75 \%)$ of its original length to fulfill various flight mission requirements. The main objective of this paper is to compare the aerodynamic characteristics for several span lengths and sweep angles and to find their most efficient combinations. The wing is optimised for different velocities during all phases of flight (min speed, loiter, cruise, and max speed) which are 17,34, 51, and 68m/s, respectively. The analyses are performed by computing forces (drag and lift) and moments at various altitudes, such as at the sea level, at 5,000 and 10,000ft. Two-dimensional aerodynamic analyses are carried out using XFLR5 code, and the ANSYS Fluent solver is used for investigating the flow field on the three-dimensional wing structure. It has been observed that a variable span morphing of tapered wing technology with a variable sweep angle can deliver up to $32.93 \%$ improved aerodynamic efficiency. This concept design can also be used for the aircraft roll motion technique instead of conventional control devices. Furthermore, the range flight mission increases up to $46.89 \%$ when the wing is placed at its full length compared to an original position. Finally, it has been concluded from this study that the wing design is more sensitive to the changing angle of the inner section and more efficient in terms of aerodynamic characteristics. 
Keywords: aerodynamic analyses; aerodynamic performance; variable span morphing of the tapered wing; UAV design

\section{NOMENCLATURE}

$\begin{array}{ll}A R & \text { Wing aspect ratio } \\ b & \text { Wingspan (m) } \\ c_{g} & \text { Geometric chord (m) } \\ C_{L} & \text { Lift coefficient } \\ C_{D} & \text { Drag coefficient } \\ C_{L} / C_{D} & \text { Lift to drag ratio } \\ c_{t} & \text { Fuel consumption rate } \\ D & \text { DRAG }(\mathrm{N}) \\ E & \text { Flight endurance }(\mathrm{h}) \\ I_{x x} & \text { Mass moment of inertia }\left(\mathrm{kgm}^{2}\right) \\ L & \text { LIFT (N) } \\ L_{r o l l} & \text { Rolling moment }(\mathrm{Nm}) \\ m_{w} & \text { Wing mass }(\mathrm{kg}) \\ p & \text { Roll rate } \\ q & \text { Dynamic pressure }(\mathrm{Pa}) \\ R & \text { Flight range }(\mathrm{km}) \\ S & \text { Wing reference area }\left(\mathrm{m}^{2}\right) \\ V & \text { Speed (m/s) } \\ W_{0} & \text { Takeoff weight }(\mathrm{N}) \\ W_{l} & \text { landing weight }(\mathrm{N}) \\ \rho & \text { Air density }\left(\mathrm{kg} / \mathrm{m}^{3}\right) \\ \tau_{s} & \text { Time constant } \\ & \end{array}$

\subsection{INTRODUCTION}

The goal of designing a morphing wing is to allow the UAV to achieve its mission requirements in various flight conditions. Enhancing the performance and improving controllability and manoeuverability of aerial vehicles have attracted considerable attention in aerospace research $^{(1-3)}$. The capability of changing the wing aspect ratio allows the UAV to achieve its mission smoothly during various flight stages $^{(4)}$. Moreover, it enables the UAV to increase its aerodynamic performance and efficiency. For instance, prolonged spans led to significant improvements in aerodynamic performance and fuel efficiency. However, they also decrease the manoeuverability and limit the cruise velocities. On the opposite side, the low aspect ratio wings give more manoeuverability and increase aircraft speed with a reduction in flight performance and an increase in fuel consumption ${ }^{(1,4,5)}$. 
The main concepts of the morphing wing can be classified into three major types as follows ${ }^{(6)}$ :

- Planform alternation: In this type, the wing can manipulate its shape dimensions, such as its span, chord length, and sweep angle.

- Out-of-plane transformation: Wing out-of-plane transformation is mainly based on three parameters, which include the span-wise bending, the chord-wise bending, and the wing twisting.

- Aerofoil adjustment: Aerofoil adjustment is mainly affected by two parameters: camber variation and thickness, which can reshape the aerofoil ${ }^{(7,8)}$.

With the growing use of the UAV in various domains, civil and military applications, the morphing aircraft technology area is reinforced in the current and upcoming periods of time ${ }^{(9)}$. The morphing concept provides massive benefits such as:

- Increasing the flight range by improving aerodynamic efficiency.

- Achieving multiple tasks to carry out radically new manoeuvers without using conventional control surfaces.

- Reducing drag force to enhance fuel efficiency, which leads to the flight envelope extension.

- Reducing vibration and flutter by enhancing structural capability.

The variable span morphing wing provides an excellent capacity for achieving multiple tasks ${ }^{(10)}$. By changing the span length and wetted area, the wing addresses numerous mission segments such as cruising, loitering, long flight range, manoeuverability, and controllability, more efficiently than a conventional wing ${ }^{(8,11,12)}$. Another advantage of adaptive span wing is the roll control through asymmetric wing changes rather than through conventional control surface. An asymmetric loading in the wing contributes to the coupling of the yawing and rolling motions ${ }^{(13,14)}$.

Numerous studies of morphing concepts have been accomplished in the last few decades ${ }^{(15-18)}$. They have been done on the advantages of the variable span morphing wing technology based on the effect of increasing aspect ratio on the performance and manoeuverability ${ }^{(19-23)}$. The majority of these studies has been focused on design and investigation of the telescopic mechanisms with rectangular wing shape at the zero sweep angle.

Ivan Makhonine has presented a variable-span wing in 1931. He designed the first telescoping wing on the MAK-10 aircraft. The mechanism allowed the span to extend up to $62 \%$ and wing space to increase up to $57 \%{ }^{(4,24)}$. The Defense Advanced Research Projects Agency (DARPA) led successful efforts to develop Morphing Aircraft Structures (MAS) from 2002 to $2007^{(25)}$. This program was defined as a multirole platform, which can change its geometrical shape according to the alteration of mission requirements, reconfigure the excellent system capability, and enable the use of innovative combinations of advanced materials, actuators, and mechanisms ${ }^{(26)}$.

Joao R. C. Mestrinho et al. designed and validated variable-span wing ${ }^{(19)}$. They have estimated the wing weight based on empirical data gained from a wing prototype. The speeds varied from 12 to $35 \mathrm{~m} / \mathrm{s}$ that was the maximum speed, while the drag reduction was $20 \%$. An analysis with asymmetric span was also carried out to estimate the rate roll. Vale et al. conducted an aerodynamic analysis of telescoping wing, and a conformal camber morphing 
for high- and low-speed aerofoils ${ }^{(23)}$. The structural optimisation was performed using the Finite Element Model to find optimal aerofoil shape and minimum weight. The comparison study was carried out between two concepts. Beaverstock et al. have done a comparison study of the influence of camber and span morphing on the mission performance of a $25 \mathrm{~kg}$ unmanned aerial vehicle ${ }^{(22)}$. The study showed the effect of the low and high velocities on the calculation of the mission parameter to increase aerodynamic efficiency and flight range. An adaptive aspect ratio span (AdAR) and a fish-bone active camber were used in this study. The results indicated that the span concept could improve the aerodynamic performance up to $25 \%$ for speeds range between 13.9 and $30.6 \mathrm{~m} / \mathrm{s}$. Tarabi et al. carried out an experimental analysis on a variable span morphing wing ${ }^{(6)}$. The model was tested in the wind tunnel at low steady wind velocities $(35,60$, and $80 \mathrm{~m} / \mathrm{s})$. The aerodynamic performance increased to $5 \%$ and $17 \%$ in flight range and endurance, respectively. R. M. Ajaj et al. ${ }^{(1)}$ have designed a new spanmorphing concept called Gear Driven Autonomous Twin Spar (GNATSpar). The wing could extend with an extra $20 \%$ to reduce drag and increase flight range. Wencheng Li and Dongping have done a study regarding the dynamical behaviour and stability of a variable-span wing ${ }^{(27)}$. The Kane method and piston theory were used to govern the equations of motion.

The results showed that the morphing wing could achieve flutter suppression, and upper bound of the morphing wing decreases swiftly at its critical span extent. Gao et al. ${ }^{(28)}$ tested and applied the Single-Degree-of-Freedom (SDOF) on the span morphing wing to improve its performance. The analysis showed that span modifications have slight effects on the lift coefficient and drag coefficient when the span changes, whereas the improvement of lift force and drag force was by $50 \%$. The results of Finite Element Methods pointed out that the base link of the mechanism was affected by the maximum stress (45.5MPa). Parkash and Pant have studied the benefits of telescoping span wing in order to increase the flight endurance for HALE UAV ${ }^{(29)}$. Three morphing configurations were determined for the Global Hawk. Two penalties were taken into account — the weight of mechanism, and the bending and shear calculations were made to gain the base weight by considering the stability characteristics.

\subsection{DEVELOPMENT OF TAPERED SPAN MORPHING MODEL}

\subsection{Description of the model}

McCormick investigated the influence of a span on aircraft dynamics ${ }^{(30)}$. It showed that aircraft with large span has good aerodynamic efficiency, which leads to a good range and fuel efficiency. On another side, aircraft with reduced span are faster and highly manoeuverable. A variable span concept is thus a good way to obtain advantages of both designs. Our study is focused on the relationship between span increase, the range, and fuel efficiency.

Furthermore, the influences of asymmetric wingspan strategy on the roll control are considered in this work, too. This study also investigates the impact of a sweep angle variation of the morphed span of the aircraft performance. The wing is divided into a fixed segment and the morphing segment. The fixed part is the basic wing without morphing. It is a straighttapered wing designed based on a NACA 4412 aerofoil. The morphing part consists of an inner section which can slide while varying its sweep angle.

In Fig. $1, l_{i}$ is the length of the wing at the original position and full extended wingspan, $\alpha$ is the sweep angle of the fixed section, and $\beta$ is the sweep angle of the inner section slide 


\section{Table 1 \\ Aerofoil parameters}

\section{Parameters for fixed wing}

The wing root chord (in meters)

Thickness at root chord

(in meter)

Max camber at root chord

(in meter)

Location of max camber at the

root chord

The wing tip chord (in meters)

Thickness at tip chord (in meter)

Max camber aft at tip chord

(in meter)

Location of max camber at tip chord

\section{Parameters for morphing part}

0.675 The wing root chord (in meters)

0.320

0.081 Thickness at root chord (in meter) 0.0128

0.027 Max camber at root chord

0.0384 (in meter)

0.27 Location of max camber at the root

0.128

chord

$0.315 \quad$ The wing tip chord (in meters) $\quad 0.290$

0.0375 Thickness at tip chord (in meter) $\quad 0.0116$

0.0126 Max camber aft at tip chord $\quad 0.0348$

(in meter)

$0.126 \quad$ Location of max camber at tip $\quad 0.116$ (a)

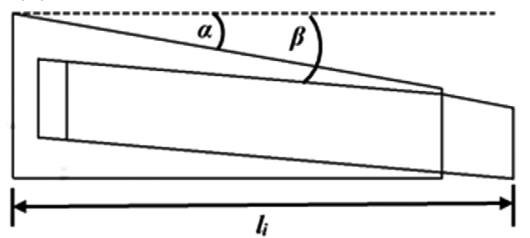

(c)

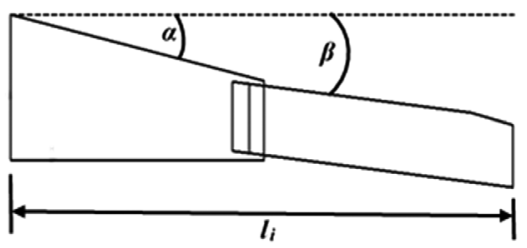

(b)

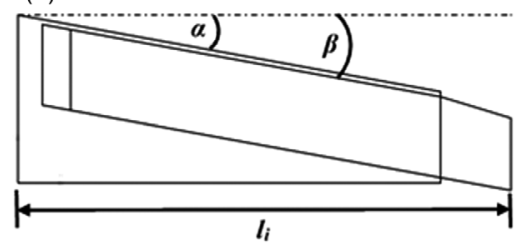

(d)

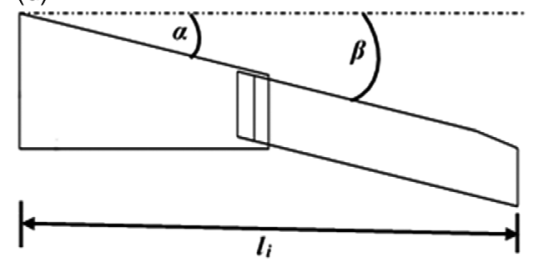

Figure 1. Morphing wing geometry of two models (a), (c): first sweep angle model (b), (d): second sweep angle model at original position and full extension.

out of the fixed wing. The focus of this work is to investigate the influence of both $l_{i}$ and $\beta$ parameters.

The inner wing is designed to have a swept angle geometrical shape according to its position in the fixed-wing. However, the end of the inner wing (about $15 \%$ of its length) is shaped as a tapered wing with the aim to fit with the fixed wing at the original position. The geometrical parameters of the morphing part as well as of the fixed $p$ used in this project are shown in Table 1.

Figure 2 shows the two configurations of the wing for two different sweep angles of their inner sections $\beta=4.5^{\circ}$ and $\beta=8.9^{\circ}$, as considered in this study. The first design configuration shows that the central axis line of the moving segment is coincident to the central axis line of the fixed wing. The second design configuration represents the leading edge of the moving segment located parallel to the leading edge of the fixed segment. 


\section{Table 2}

\section{Wing parameters}

\section{Parameter}

The wing half-span (in meters), $b / 2$

The wing area (in square meters), $S$

The wing root chord (in meters), $c_{r}$

The wing tip chord (in meters), $c_{t}$

Aspect ratio, $A R$

The taper ratio, $\lambda$

The mean aerodynamic chord in meter $\bar{c}$

MAC distance from root chord

$\begin{gathered}\text { Original } \\ \text { Wing }\end{gathered}$
2.100
1.921
0.675
0.290
9.18
0.43
0.51
0.91

$25 \%$ Extension

2.625
2.258
0.675
0.290
12.2
0.43
0.51
1.14

$50 \%$ Extension

3.150
2.595
0.675
0.290
15.29
0.43
0.51
1.37

$75 \%$

Extension

3.675

2.933

0.675

0.290

18.42

0.43

0.51

1.59
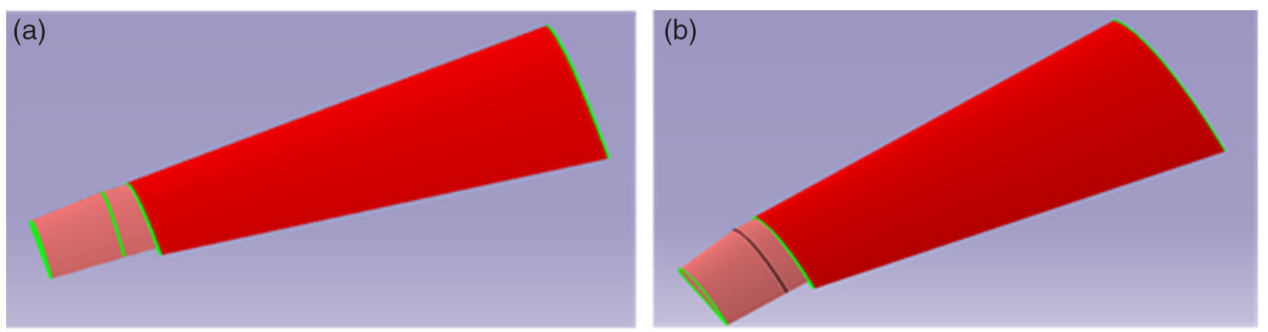

Figure 2. Variable span of the tapered morphing wings for (a): the first sweep angle model and (b): second sweep angle model.

Both configurations of the wing are designed using Computer-Aided Design (CAD) with CATIA software and allow three various span extensions. Table 2 shows the wing geometries of their two configurations at the original position and for the specific span extensions.

\subsection{AERODYNAMIC ANALYSIS}

\subsection{Aerodynamic wing studies using XFoil and ANSYS fluent}

The aerodynamic investigation is performed in two steps. First, the 2-dimensional (2D) aerodynamic analysis used XFOIL code to obtain aerodynamic forces and moments coefficients as functions of Reynolds number $(R e)$ and the angle-of-attack $(A O A)$. The Vortex Lattice Method is used for numerical analysis based on XFLR5 code solver. The aerodynamic coefficients were conducted at various Reynolds numbers and angles of attack. The aerofoil was operated at Reynolds numbers of $(610263,1220525,1830788$, and 2441050 relatively to the chord), which correspond to speeds of $0.05,0.10,0.15$, and 0.20 Mach. The selected angles of attack were ranged between $-3^{\circ}$ and $15^{\circ}$.

Moreover, the number of panels was 160 , with the aim of obtaining more realistic results. The NACA 4412 includes four-digit code used to define the aerofoil by:

- The first digit gives the maximum camber in terms of a percentage of the chord, more specifically $4 \%$ of the chord length. 


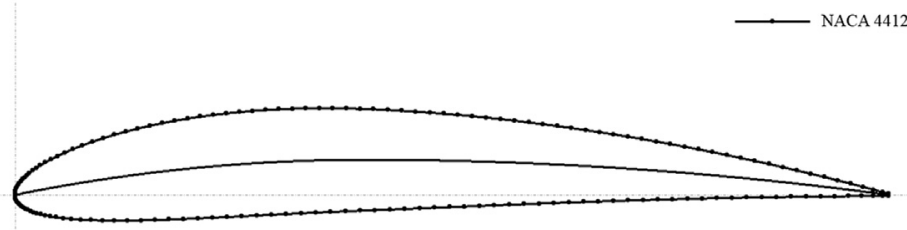

Figure 3. Geometry of the NACA 4412 aerofoil.

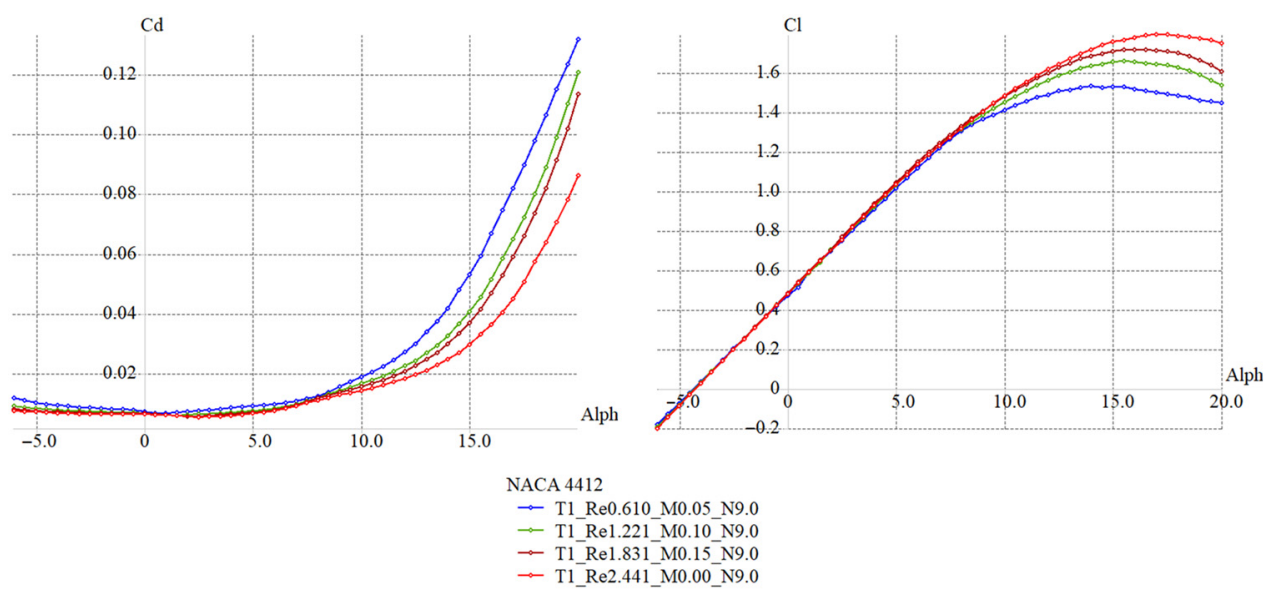

Figure 4. Lift and drag coefficients variation versus the angle-of-attack.

- The second digit gives the location of maximum camber from the aerofoil leading edge in 10 's of the chord percentage, such as $40 \%$ from the aerofoil leading-edge.

- The third and fourth digits give the maximum thickness of the aerofoil in terms of percentage of the chord, such as $12 \%$ of the chord length ${ }^{(31)}$.

The NACA 4412 aerofoil geometrical shape is shown in Fig. 3.

The variation of lift and drag coefficients with the angle-of-attack are shown in Fig. 4; these variations were obtained by the use of the XFLR5 software which uses both Xfoil algorithms and the Vortex Lattice Method ${ }^{(32)}$.

Once the aerodynamic characteristics for the NACA 4412 aerofoil have been analysed numerically in XFLR5 solver, the novel design concept for creating the span morphing wing was developed. The variable span morphing wing, proposed in this study, aims to benefit from the aerodynamic and structural advantages of tapered wing shape. The main benefits of tapered span design with respect to its baseline design wing might be, for example, better aerodynamic efficiency (lower drag and better lift distribution along its span), better structural efficiency (stronger and lighter) as the chords lengths are varying between the root and tip, and manoeuverability would be better. The lift to drag ratio efficiency influence by the taper ratio at the low flight speed ${ }^{(33)}$.

Second, by the numerical investigations four versions (based on the wingspan extension stages) of Variable Span Morphing of Tapered Wings (VSMTW) are implemented by using a Computational Fluid Dynamics (CFD) ANSYS Fluent solver that is used as it can 
(a)

(b)

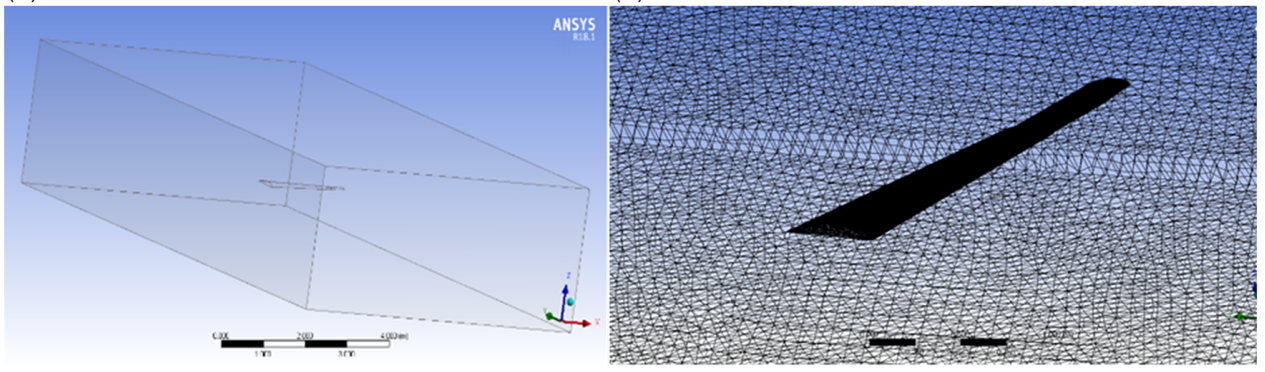

Figure 5. Numerical analysis phases using ANSYS Fluent.

offer beneficial tools for geometry editing, meshing, simulation setup, and results of the analysis $^{(34)}$. The use of ANSYS Fluent solver provides accurate solutions and speeds up the simulations of complex scenarios such as transonic or turbulent flows. The results obtained from this numerical study will be analysed for the variable morphing wingspan experimental performance validation using a wind tunnel. In this comparative design study, the following procedure is performed for both sweep angle models ${ }^{(35,36)}$.

- The geometrical shape and physical outlines of the design are determined using ComputerAided Design (CAD) as represented in Fig. 2.

- The data is then processed, and the fluid chamber volume (or fluid domain) is defined.

- The fluid volume and the wing shape are divided into discrete cells (meshes). The number of elements and nodes is varied as the wing length change and in correlation with the wing geometrical shape. The physical modelling is selected based on the equations of fluid motions.

- For the simulation, boundary conditions, such as fluid behaviour and properties (density, speeds, viscosity, pressure, etc.), must be defined.

- To obtain the final solution, and to visualise the results, a postprocessor is used after solving the equations iteratively, which allows creating contour plots, vector plots, 2D and 3D surface plots, etc. Moreover, it can offer animation for dynamic results display.

Figure 5 shows the numerical analysis methods carried out in this study using ANSYS Fluent solver.

The 3D unstructured tetrahedral mesh for both design shapes was employed for the flow around the model. For more accuracy, the "inflation layers" were applied to smooth the mesh of edges around the wing surface. Thus, the inflation layers provide a highly precise resolution of the boundary layer. The number of ten inflation layers was situated within the boundary layers to obtain the accurate solving of the boundary layer. The meshing method is described in Fig. 5(b). The two modelling methods based on the Reynolds-Averaged Navier-Stokes (RANS) were applied for computing the flow past the wing. First, by the k- $\varepsilon$ turbulence model was used to simulate mean flow characteristics around the wing to investigate the turbulent flow conditions, because of the fact that the free-shear layer flows with relatively small pressure gradients. The k-epsilon model was based on two equations, and it provided the flow simulation, including its rotation, recirculation, and separation ${ }^{(37)}$. According to the results obtained with means of the k- $\varepsilon$ model, two wing design shapes (with two sweep angles) were selected among their preliminary design shapes; thereafter, the Transition Shear-Stress 


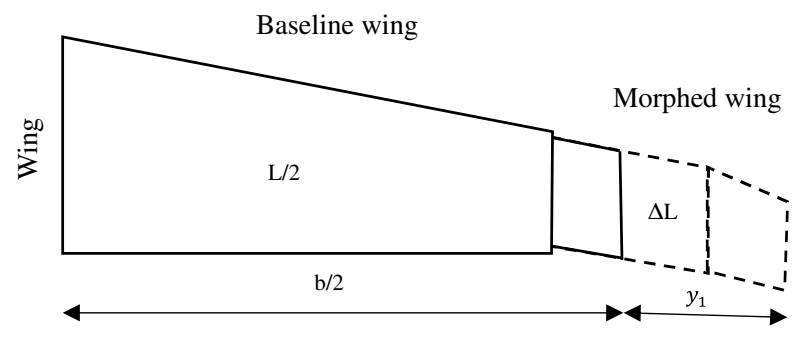

Figure 6. Increase of wing span $y / b(\%)$.

Transport (Transition SST) turbulence model was implemented as it could predict correctly the flow separation, provide robust accurate results including steady-state solutions ${ }^{(38,39)}$. The Transition SST turbulence model was based on four equations and solves flow turbulence for smooth transition based on the $\mathrm{k}-\Omega$ model near the wall. Transition SST turbulence model is rated for aerodynamic applications as one of the most precise model used for aerodynamic performance evaluation. Boundary condition, solution control parameters and material properties were defined.

\subsection{Aerodynamic performance and mission range}

To evaluate the performance improvements, the rolling moment, the roll rate, the range, and the endurance was calculated from the aerodynamic coefficients obtained using the morphing technique.

\subsubsection{Rolling moment calculation}

The adjustment of the variable-span wing asymmetrically is predicted to obtain rolling moment as given otherwise by conventional ailerons. However, the challenge of this technique is from the structural viewpoint; the root wing will be influenced by considerable sizeable bending moment ${ }^{(40)}$. The bending moment of a variable wingspan increases as the product of lift distribution, wing area, wing panel span, and free-stream dynamic pressure increases due to the span extension. Weight is also a critical factor for increasing the bending moment, especially when an added actuation system would be located at the wing root. According to some studies ${ }^{(20)}$, the root bending moment of a variable wingspan can be $60 \%$ higher than the root bending moment of conventional ailerons.

The semi-span of one side extends to the desired distance $y_{1}$ while maintaining the other side fixed, as shown in Fig. 6.

The total lift at the beginning of the roll motion can be determined as Ref. 40:

$$
L+\Delta L=q C_{L}(S+\Delta S)
$$

where $L$ is the lift produced by the original wing, $\Delta L$ is the acquired lift due to span extension, $q$ is the dynamic pressure, $C_{L}$ is the lift coefficient, $S$ is the original wing area, and $\Delta S$ is the additional wing area after span extension. The lift is equal on both sides of the wing due to its symmetric span. However, as the wing area changes on one side due to the asymmetric span extension or retraction, the lift will increase more on one side of the wing. 
The area $S$ of a tapered wing and the changing area $\Delta S$ of the swept angle geometrical shape of wing become:

$$
S=b * \frac{\left[c_{r}+c_{t}\right]}{2}
$$

where $b$ is the wingspan at the original wing, $c_{r}$ is the root chord, and $c_{t}$ is the tip chord.

The changing area is:

$$
\Delta S=\frac{\left[c_{r}+c_{t}\right]}{2} * y_{1}
$$

where $y_{l}$ is the additional wingspan after span extension, $c_{r}$ is the root chord, and $c_{t}$ is the tip chord.

The total lift coefficient can be found with the following equation.

$$
C_{L}=\frac{L+\Delta L}{q * \frac{\left[c_{r}+c_{t}\right]}{2}\left(b+y_{1}\right)}
$$

The rolling moment $L_{\text {roll }}$ can be approximated with the following equation ${ }^{(40)}$ :

$$
L_{\text {roll }} \approx \Delta L\left(\frac{b}{2}+\frac{y_{1}}{2}\right) \approx q * \frac{\left[c_{r}+c_{t}\right]}{2} y_{1} C_{L}\left(\frac{b}{2}+\frac{y_{1}}{2}\right)
$$

As the assumption of the equation, the lift influences in the midpoint of the wing extension, because of that, it has a total moment arm of $\left((b / 2)+\left(y_{1} / 2\right)\right)$. By substituting Equation (4) in the rolling moment Equation (5), the Equation (6) becomes:

$$
L_{\text {roll }}=\frac{L+\Delta L}{2} y_{1}
$$

where $L_{\text {roll }}$ is the rolling moment, $L$ is the lift at the original position, and $\Delta L$ is the gained lift through span extension.

The Equation (6) shows that by extending the wing on one side, the rolling moment produced relies on the difference between a generated lift in both semi-span.

\subsubsection{Roll rate}

The asymmetric span configurations can vary the lift distribution in morphing wing. For example, when one side of the wing (starboard or port) extends its span longer than the other side of the wing, the lift distribution symmetry point will transfer to the long wingspan ${ }^{(41)}$. The generated roll moment is expected to be the one given by the deflection of conventional ailerons for roll manoeuvers control ${ }^{(40)}$. For the pure roll rate due to varying mass moment inertia, the first-order equation can be defined as Refs. 21 and 40:

$$
L_{\text {roll }}=I_{x x} \dot{p}+p \dot{I}_{x x}
$$

Where $I_{x x}$ is the mass moment of inertia around the $x$-axis and $p$ is the roll rate. With the assumption of wing mass distribution, and neglection of the contribution of other components 
such as fuselage and empennage, the equation of mass moment of inertia becomes:

$$
I_{x x} \approx \frac{m_{w} b^{2}}{12}
$$

where $m_{w}$ the mass of wing. The mass moment of inertia with variable-span wing can be expressed by:

$$
I_{x x_{s}}=I_{x x}+\frac{m_{w}}{6}\left(y_{1}^{2}+y_{2}^{2}+b y_{1}+b y_{2}\right)
$$

$I_{x x s}$ is a mass moment of inertia with variable-span wing around the $x$-axis, and $y_{1}, y_{2}$ are the extensions of starboard and port, respectively. In the previous equations, the mass moment of inertia of fuselage and empennage are neglected. Hence, the rate of alteration of the wing inertia is time-dependent and is defined as:

$$
\dot{I}_{x_{s}}=\frac{m_{w}}{6}\left(2 y_{1} \dot{y}_{1}+2 y_{1} \dot{y}_{2}+b \dot{y}_{1}+b \dot{y}_{2}\right)
$$

Based on the Equation (7), the rolling moment equation for span morphing can be defined as Refs. 40 and 42:

$$
L_{\text {roll }}=I_{x x_{s}} \dot{p}+p \dot{I}_{x x_{s}}=\frac{\partial L}{\partial y_{1}} y_{1}+\frac{\partial L}{\partial y_{2}} y_{2}+\frac{\partial L}{\partial p} p
$$

where $\left(\partial L / \partial y_{1}\right) y_{1}+\left(\partial L / \partial y_{2}\right) y_{2}$ is the roll moment due to the extension of starboard and port, respectively, and $(\partial L / \partial p) p$ is the roll damping moment. To alleviate the bending moment at the wing root, the appropriate extensions of both wing sides should be determined at a given flight condition ${ }^{(42)}$. Therefore, the governing equation of rolling motion becomes.

$$
I_{x x_{s}} \dot{p}-\left(\frac{\partial L}{\partial p}-\dot{I}_{x x_{s}}\right) p=\frac{\partial L}{\partial y_{1}} y_{1}+\frac{\partial L}{\partial y_{2}} y_{2}
$$

where

$$
\frac{\partial L}{\partial p}=\frac{\rho V \bar{c}\left(b+y_{1}+y_{2}\right)}{4} C_{l_{p s}}
$$

and

$$
C_{l p s}=\frac{\pi\left(b+y_{1}+y_{2}\right)}{3\left(b+y_{1}+y_{2}+2 \bar{c}\right)}
$$

where the $C_{l p s}$ is the rolling moment damping coefficient.

The steady roll rate is determined by:

$$
L_{p_{s}}=\frac{\left(\frac{\partial L}{\partial p}-\dot{I}_{x x_{s}}\right)}{I_{x x}}
$$




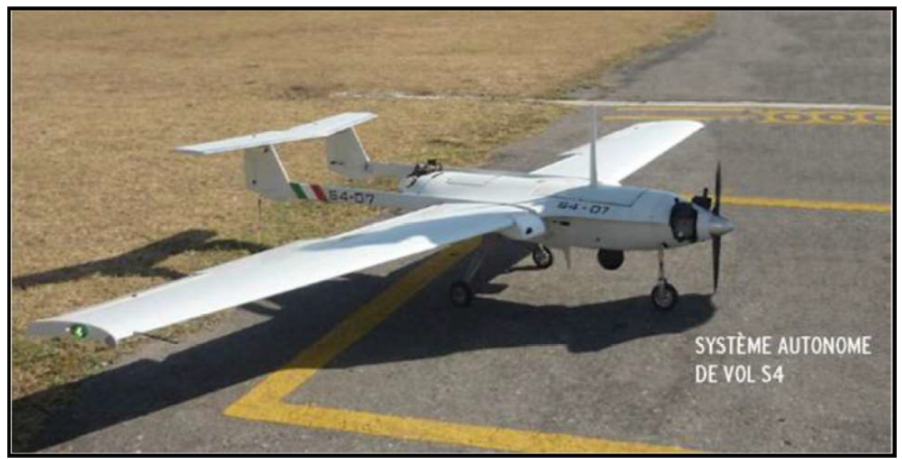

Figure 7. Hydra technologies UAS-S4 Ehecalt.

and

$$
L_{\partial y}=\frac{\left(\frac{\partial L}{\partial y_{1}}+\frac{\partial L}{\partial y_{2}}\right)}{I_{x x}}
$$

The time constant $\tau_{s}$ is time for roll mode response.

where the time constant can be defined as:

$$
\tau_{s}=-\frac{4 I_{x x_{s}}}{\rho V c\left(b+y_{1}+y_{2}\right)^{3} C_{l_{p s}}}
$$

The steady state roll rate of the variable-span wing is Ref. 42:

$$
p_{s s}^{*}=-\frac{\left(\frac{\partial L}{\partial y_{1}}+\frac{\partial L}{\partial y_{2}}\right)}{L_{p}^{*}}\left(\partial y_{1}-\partial y_{2}\right)
$$

\subsubsection{Improved range and endurance estimation}

The efficiency of the morphing wing was also estimated in terms of range and endurance increases. As the wingspan extends, the aerodynamic performance (lift-to-drag) increases, thus increasing the range and endurance contribute to an improvement of aircraft efficiency. For the purpose of investigating the increase of performance, the geometrical characteristic of a real aircraft was considered.

The estimations were made using the characteristic of the UAS-S4 ${ }^{(43-45)}$. The UAS-S4 is an unmanned aerial system designed and manufactured by Hydra technologies for the military and civilian purpose (Fig. 7). Its general characteristics are presented in Table 3.

The range and endurance of the UAS-S4, assuming steady level flight based on the Breguet formulas are $^{(46)}$ :

$$
\begin{gathered}
R=\frac{\eta}{c} \frac{C_{L}}{C_{D}} \ln \frac{W_{0}}{W_{1}} \\
E=\frac{\eta}{c} \frac{C_{L}^{3 / 2}}{C_{D}} \frac{\sqrt{2 \rho_{\infty} S}}{\sqrt{W_{1}}-\sqrt{W_{0}}}
\end{gathered}
$$


Table 3

The characteristics of the UAS-S4

Geometrical Data

Wing span

Wing area

Total length

Mean Aerodynamic Chord (MAC)

Empty weight

Maximum Take-off Weight (MTOW)

Loitering airspeed

Maximum speed

Service ceiling

Operational range
Values

$4.2 \mathrm{~m}$

$2.3 \mathrm{~m}^{2}$

$2.5 \mathrm{~m}$

$0.57 \mathrm{~m}$

$50 \mathrm{~kg}$

$80 \mathrm{~kg}$

$35 \mathrm{kn}$

$135 \mathrm{kn}$

$15,000 \mathrm{ft}$

$120 \mathrm{~km}$

\section{Table 4}

The increase of the aerodynamic efficiency for selected speeds from wing original position to its full span extension

$$
\text { First Shape, } \beta=4.5^{\circ}
$$

Original

Position

23.358

23.760

24.337

$C_{L} / C_{D}$ at Loiter speed

$C_{L} / C_{D}$ at Cruise speed

$C_{L} / C_{D}$ at Max speed
Increase Original

$75 \%$

30.112

31.392

32.350

Second Shape, $\beta=8.9^{\circ}$

Where $R$ and $E$ are the range and endurance, $\eta, c, W_{0}$, and $W_{l}$, are the propulsive efficiency, the fuel consumption rate, takeoff weight, and landing weight, respectively. For a given morphing aircraft, in Equations (19) and (20), the values of airspeed and weight are constant.

Note that for a given altitude and weight, the range and endurance are maximised when the $\frac{C_{L}}{C_{D}}$ and $\frac{C_{L}^{3 / 2}}{C_{D}}$ are maximum ${ }^{(47)}$. Their maximum values are given by the following equations:

$$
\begin{gathered}
\left(\frac{C_{L}}{C_{D}}\right)_{\text {max }}=\left(\frac{C_{D_{0}} * \pi * e * A R}{2 * C_{D_{0}}}\right)^{1 / 2} \\
\left(\frac{C_{L}^{3 / 2}}{C_{D}}\right)_{\text {max }}=\left(\frac{3 * C_{D_{0}} * \pi * e * A R}{4 * C_{D_{0}}}\right)^{3 / 4}
\end{gathered}
$$

Where $e$ is span efficiency factor, and $C_{D 0}$ is zero-lift drag coefficient.

The aerodynamic efficiency is dependent on the wing aspect ratio. As a result, an increase in wing aspect ratio would lead in the boost up of both flight range and endurance. Moreover, the flight endurance is further increased for a variable wing because the wing area also increases based on a change of aspect ratio. 


\subsection{PERFORMANCE EVALUATION OF DESIGNED MODELS}

This comparative study gives an evaluation of the performance characteristics for selecting the best geometrical shape. The results obtained in this work include varying parameters obtained using Computational Fluid Dynamics (CFD) solver. The wings have been designed by considering advantages of the structural and aerodynamic design point of views. For accomplishing the simulation processes, the morphing wing span has been extended in this investigation by $25 \%, 50 \%$, and $75 \%$ of the original wing. The analyses were carried out at four airspeed values, $17,34,51$, and $68 \mathrm{~m} / \mathrm{s}$, corresponding to Mach number values of 0.05 , $0.10,0.15$, and 0.20 , respectively. Furthermore, the air density and dynamic pressure were determined at various altitudes, such as at the sea level, at 5,000 and 10,000ft.

\subsection{Comparison results obtained for aerodynamic efficiency}

The results present the comparison of the aerodynamic efficiency variation for the various airspeeds, for which the length and the sweep angle of the inner section were varied. Figure 8 shows the variation of the lift coefficient with the drag coefficient $\left(C_{L}\right.$ vs $\left.C_{D}\right)$ changes substantially for the first and second sweep angle models $\left(\beta=4.5^{\circ}\right.$ and $\left.\beta=8.9^{\circ}\right)$, respectively, when both wingspan and speed vary (lift increase and drag decrease). However, as seen in Fig. 8, the aerodynamic performance generated by varying the wingspan length was more efficient than that generated by varying the speed at all selected altitudes in this investigation. For instance, the lift and drag coefficients obtained at sea level for the entire wing were equal to 0.350 and 0.0123 for the first sweep angle model, and were equal to 0.340 and 0.0122 for the second sweep angle model at low speed (Mach number of 0.05), and for full wingspan extension.

On the other hand, the lift and drag coefficients at maximum speed (Mach number of 0.2) but the original position were of 0.362 and 0.0109 , and of 0.352 and 0.0109 for the first and second sweep angle models, respectively.

Furthermore, the main parameters in this investigation are the sweep angle of the moving segment inside the fixed wing, the wingspan, and the flight speed variation. However, the effects of these two parameters (wingspan lengths and flight speeds variations) on the UAV wing are different for the two sweep angles models. For instance, it is evident that the increase of the wingspan length (at the same flight speed) can conduct, for example, to the increase of the lift coefficient at the cruise speed. Therefore, when the wing extended to $75 \%$ from its original length, for the first and the second sweep angle models, the lift coefficient increased up to $11 \%$ and up to $9.4 \%$, respectively. It was noticed that the lift coefficient increases with the sweep angle decrease. Moreover, the drag coefficient decreased for the first and the second sweep angle models, up to $16.2 \%$ and up to $12.3 \%$, respectively (it decreased with the decrease of the sweep angle).

On the other side, by taking into account the varying speed, for example, when the wingspan was at $75 \%$ of its length, and the speed varied from its minimum to its maximum value, the lift coefficient increased up to $3.6 \%$, and $3.3 \%$ for the first and the second sweep angle model, respectively. The drag coefficient reduced to $12.7 \%$ and to $11.1 \%$, respectively, for the first, and the second sweep angle models.

Figure 9 illustrates that the performances of the wing with the first sweep angle model $\left(\beta=4.5^{\circ}\right)$ are more effective than the performances of the wing with the second sweep angle $\operatorname{model}\left(\beta=8.9^{\circ}\right)$. 
(a) Lift Coefficient vs Drag Coefficient First Model at Sea level

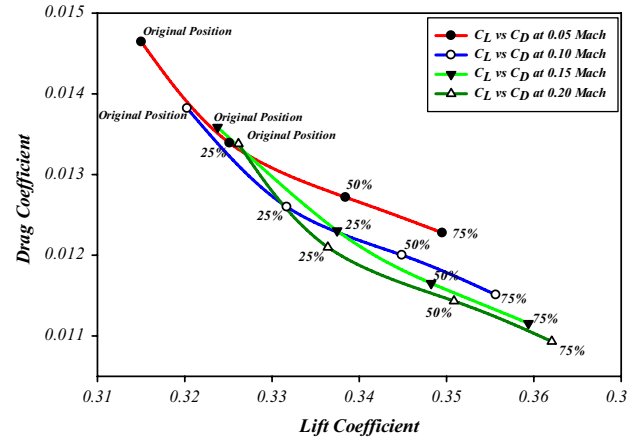

(a) Lift Coefficient vs Drag Coefficient First Model at 5000ft

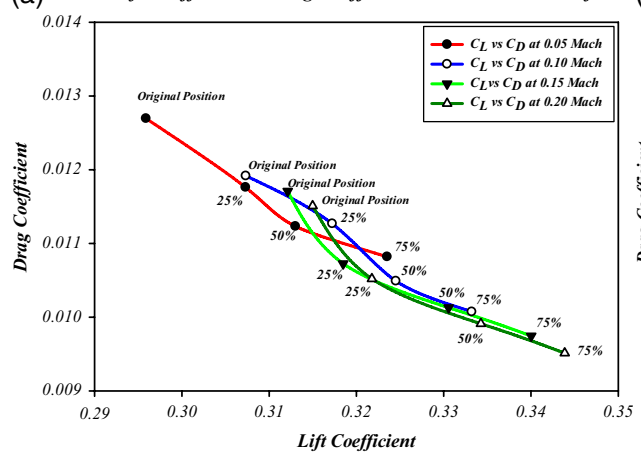

(a) Lift Coefficient vs Drag Coefficient First Model at 10000ft

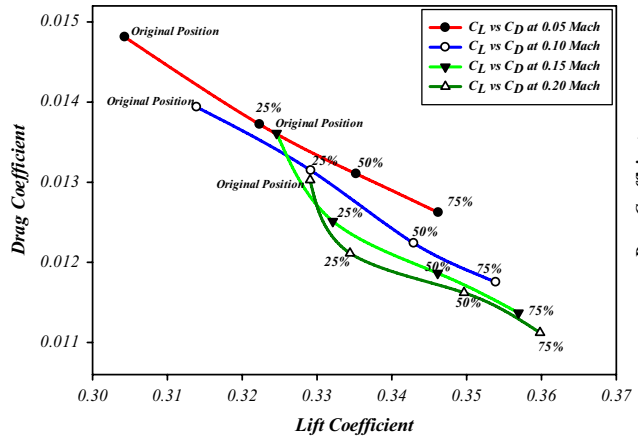

(b) Lift Coefficient vs Drag Coefficient Second Model at Sea level

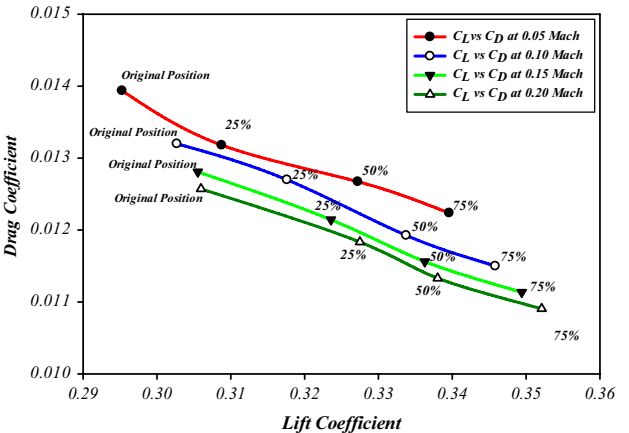

(b) Lift Coefficient vs Drag Coefficient Second Model at 5000ft

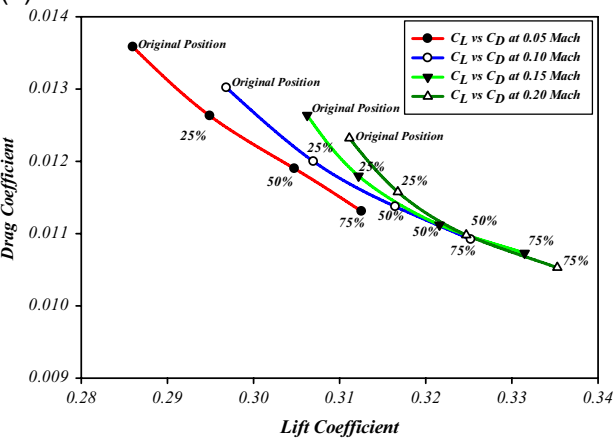

(b) Lift Coefficient vs Drag Coefficient Second Model at 10000ft

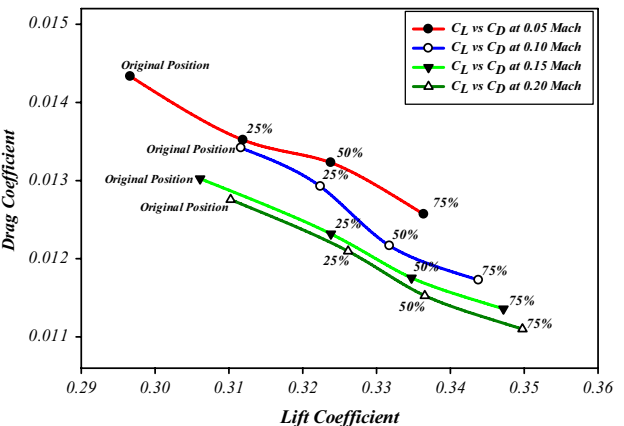

Figure 8. Drag coefficient versus lift coefficient of span extension at various velocities for (a) first sweep angle model and (b) second sweep angle model at sea level, 5,000ft., and 10,000ft.

The aerodynamic efficiency, for instance, increases with the full-extended span at the cruise speed and altitude $1,000 \mathrm{ft}$ for the first sweep angle configuration to 31.39 , and the second sweep angle configuration to 30.57 . Therefore, the improving ratio of aerodynamic efficiency for both configurations at this speed when span extends from its original position to its full extension was of $32.39 \%$ and $29.5 \%$, respectively. For more details, Table 4 contains the values of aerodynamic efficiency for span configuration extension at selected speeds.

The results indicate that as the span increases, the aerodynamic efficiency increases. Figure 10 shows the drag coefficient versus the lift coefficient variations for the four morphing 

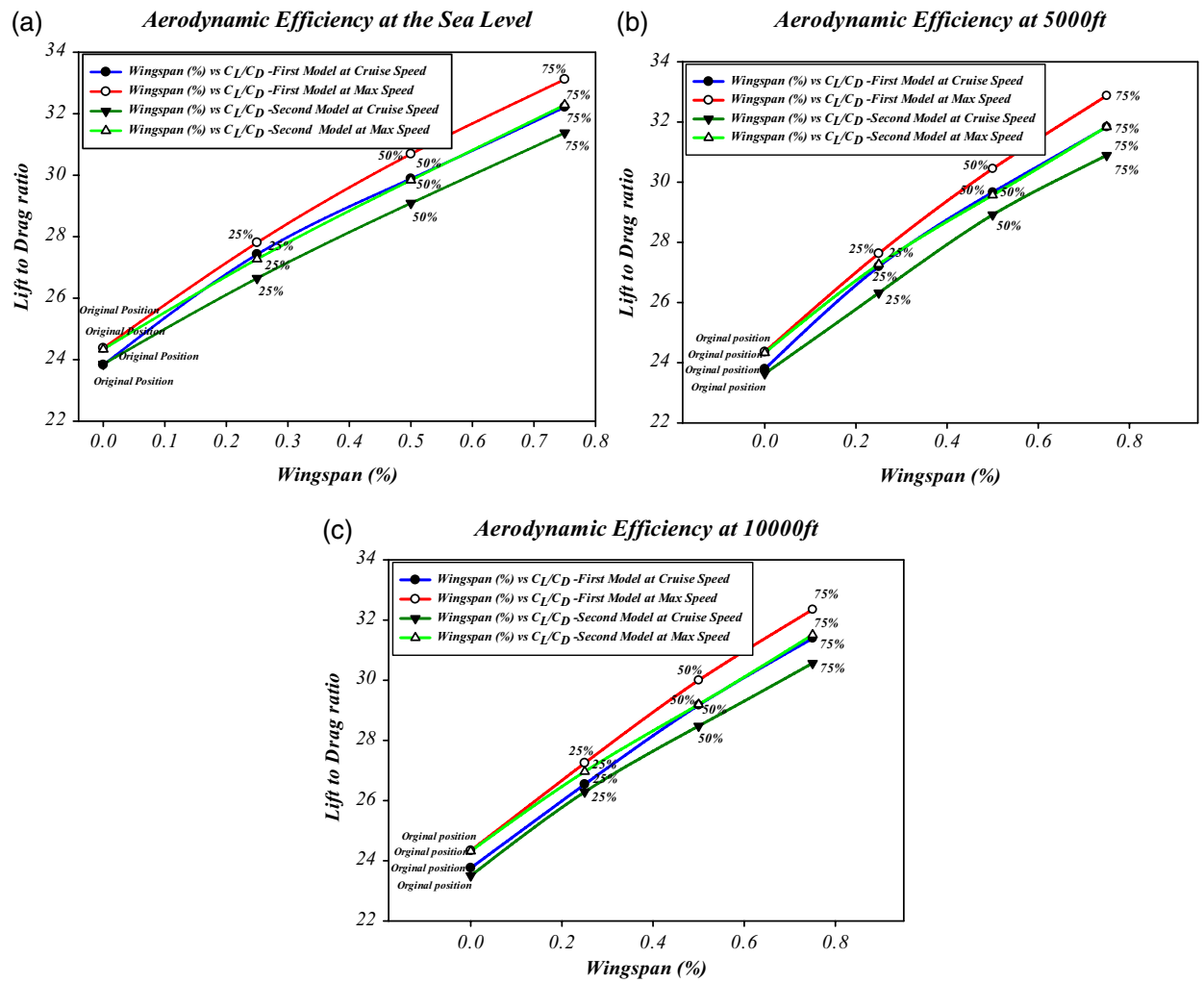

Figure 9. Aerodynamic efficiency comparison at cruise and maximum speed at (a) the sea level, (b) at $5,000 \mathrm{ft}$. and (c) 10,000ft.

wing configurations at the sea level, at 5,000 and 10,000ft altitudes. As expected, changing from the original position to maximum span extension increases the lift coefficient, and decreases drag coefficient, therefore, the maximum lift coefficient increases, and the induced drag decreases. Since the angle-of-attack is constant at $0^{\circ}$ in this investigation, therefore, the effect of angle-of-attack on the wing is out of scope for this study. Thus, the aerodynamic efficiency increases based on the influence of wingspan extension $(0 \%, 25 \%, 50 \%$, and $75 \%$ ), and the variation of the speed (Mach numbers of $0.05,0.10,0.15$, and 0.20 ) for two sweep angle models. The aerodynamic performance rate for each extended span decreases slightly for both configurations. For example, the aerodynamic performance rate differs in the first sweep angle configuration, at 10,000ft altitude and at the cruise speed when the span is extended from its original position to $25 \%$, from $25 \%$ to $50 \%$, and from $50 \%$ to $75 \%$ of its length to $11.70 \%, 9.92 \%, 7.61 \%$, respectively. In the same way, as in the first sweep angle configuration, the aerodynamic performance rates for the second sweep angle configuration are $11.65 \%, 8.48 \%$, and $7.33 \%$, respectively. Table 5 contains all aerodynamic performance values for first sweep angle model and second sweep angle model at cruise and maximum speed. The induced drag average based on the full-extended span (from the original position to $75 \%$ of its length) decreased to approximately $7 \%$ for both shapes at all selected speeds. 
Table 5

The increasing rate of aerodynamic performance for the first and second sweep angle models when span length changes at cruise and maximum speeds

\section{$51 \mathrm{~m} / \mathrm{s}$ (Cruise)}

\section{First Model Second Model First Model Second Model}

Original position $-25 \%$

$25 \%-50 \%$

$11.7 \%$

$50 \%-75 \%$
$9.92 \%$

$7.61 \%$
$11.35 \%$

$8.48 \%$

$7.33 \%$
68m/s(Maximum Speed)

$11.96 \%$

$10.86 \%$

$10.1 \%$

$9.16 \%$

$7.83 \%$

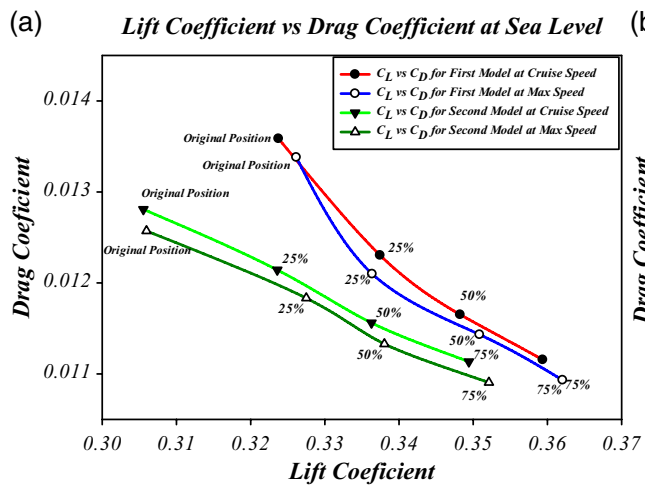

(b) Lift Coefficient vs Drag Coefficient at 5000ft

(c) Lift Coeficient vs Drag Coeficient at 10000ft

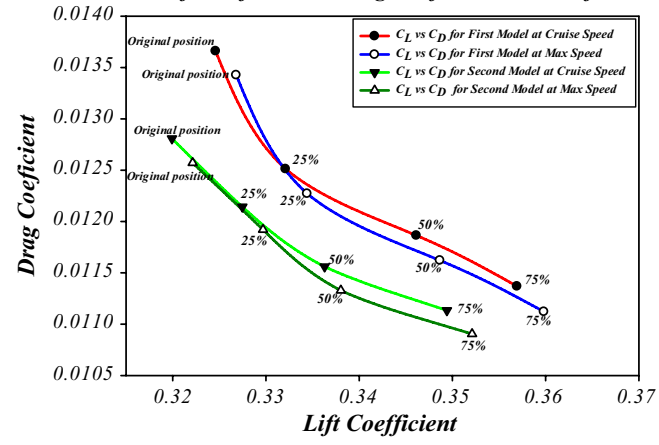

Figure 10. Drag coefficient versus lift coefficient variation at (a) the sea level, (b) at 5,000ft., and (c) at 10,000ft.

It is clear that the change of the position of the moving wing axis inside the fixed-wing noticeably influences the performance of the morphing wing. For instance, the difference in aerodynamic performance between the first and the second sweep angle configuration suggests that the difference in the improvement of performance between the first sweep angle and the second one reached up to $27.43 \%, 28.44 \%$, and $28.81 \%$ for loiter, cruise, and max speed respectively, when wingspan is modified to full extended span. 

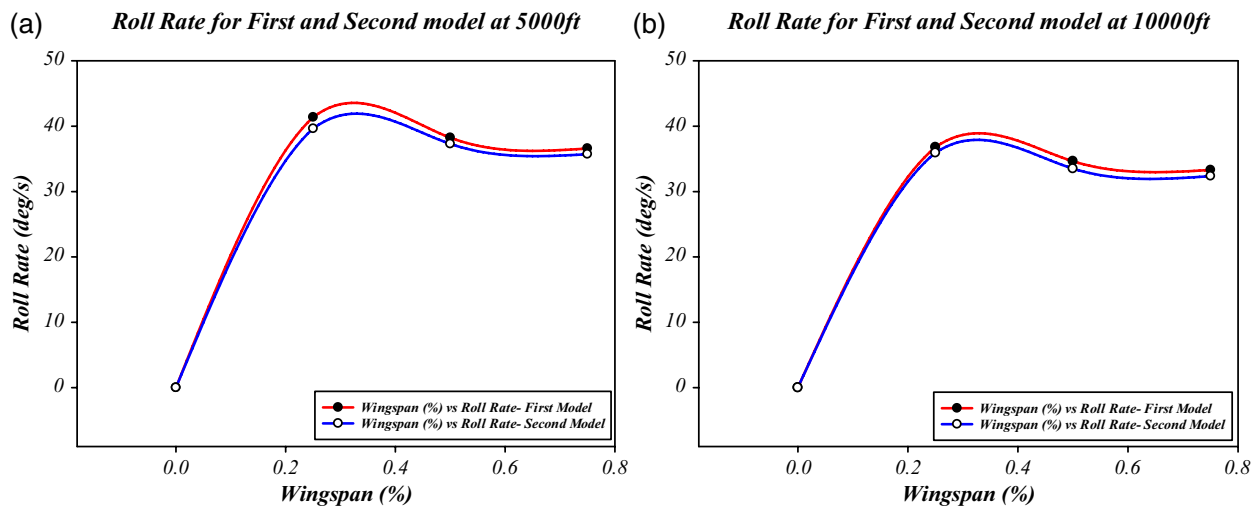

Figure 11. Roll rate versus the wingspan locations for the first and second sweep angles model (a) at $5,000 \mathrm{ft}$. and (b) 10,000ft.

\subsection{Asymmetric span morphing at cruise and maximum velocity}

As one of the benefits of a variable morphing wing, the roll control is accomplished by using different spanwise lift distribution between the port wing (PW) and the starboard wing (SBW). However, it is obvious that this technique is not the best method to achieve roll control due to the structural perspective because of the increasing of the bending moment at the wing root noticeably. Thus, the reinforcement of the wing structure must be taken into account in the mechanical design and optimisation to overcome the bending moment increase. The roll control must be calculated for the differential of span extension. Span retraction of varying extension rates (from $75 \%$ to original wing) is applied, where the rate of change is held constant from maximum to minimum. The results in Fig. 11 indicate that increasing span leads to delay in the roll rate while decreasing span tends to speed up the roll rate Equation (18) as shown in Fig. 11 for both altitudes of 5,000 and 10,000ft. On the contrary, Fig. 12 illustrates that the roll damping moment increases as the wingspan increases.

The roll rate increases significantly as the speed increases. As the flight speed increases, the tendency of the aircraft reduces to roll, as the damping increases, which is very consistent with the rolling moment damping coefficient. The purpose of this study is to compare two design options for selecting the best shape in terms of the performance of three characteristics (aerodynamic, roll control, and range and endurance). The results of the rolling moment damping coefficient Equations (13) and (14), are shown in Fig. 12, indicate that the first sweep angle generates a more rolling moment as the span increases. Nevertheless, the changing of the rolling moment is about $2.8 \%$ at full span extension.

It can be summarised that the asymmetrical variable span can be used for rolling control, and it can achieve steady turns. Since generating the lift distribution is different for the first and the second sweep angle model in the present case, the rolling moment coefficient is slightly larger for the first sweep angle model as shown in Fig. 13. The time constant of roll mode response is identical for both sweep angles models as the parameters in Equation (17) are constant. Figure 14 refers to the time response of both variable morphing span wing models for roll control at the altitudes of 5,000 and 10,000ft. The rolling time constant increases with the wings span location, as seen on Fig. 14. 


\section{Rolling Moment Damping Coefficienf for First and Second Model}

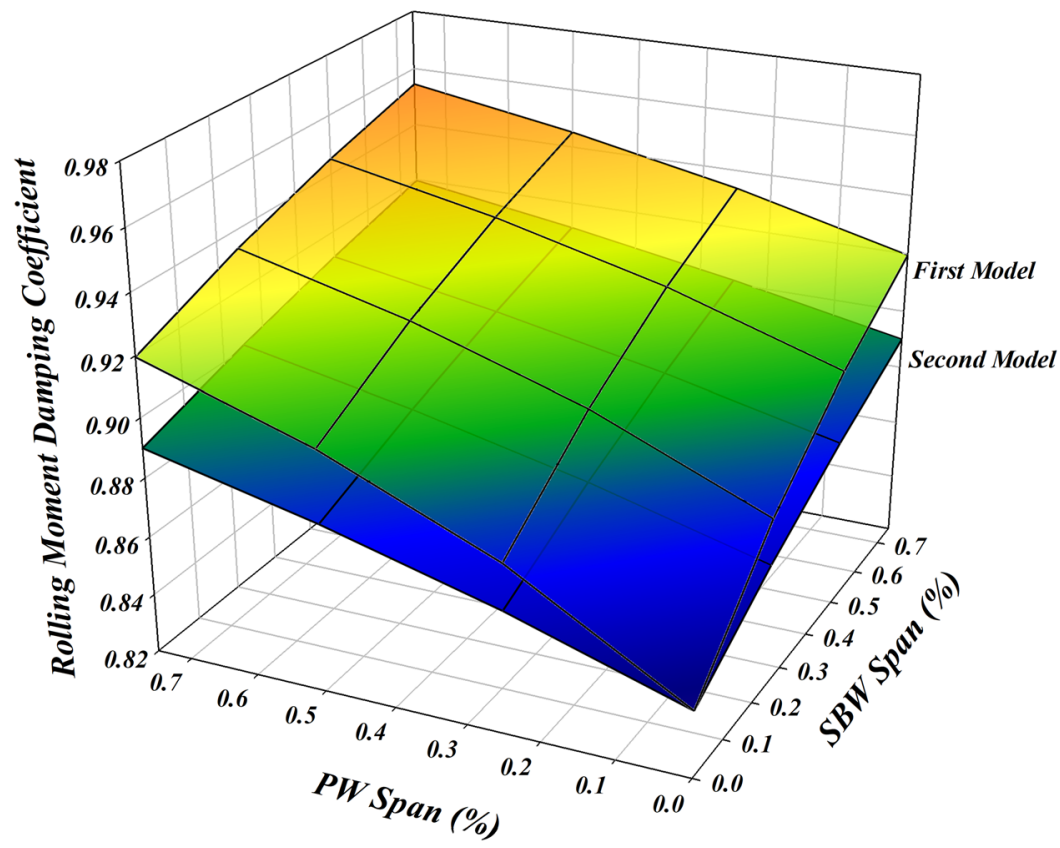

Figure 12. Rolling moment damping coefficient for the first and second Model PW: port wing, SBW: starboard wing.

(a)

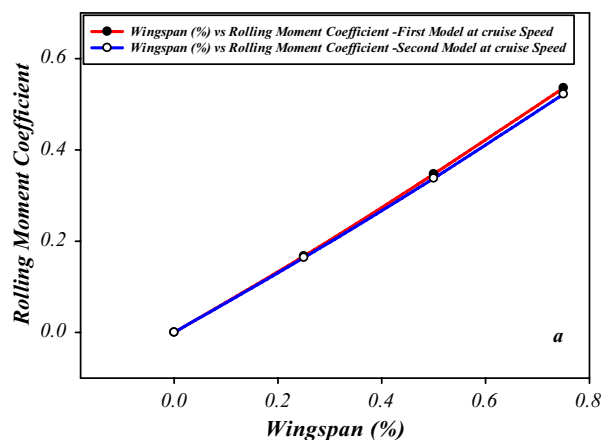

(b)

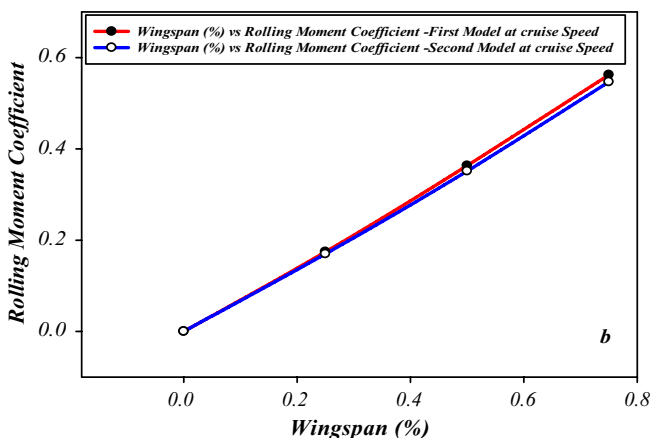

Figure 13. Rolling moment coefficient versus wingspan locations for the first and second sweep angle models (a) at 5,000ft. and (b) 10,000ft.

\subsection{Comparison results for the range and the endurance}

The results provide a clear image of the benefits of a variable morphing wing for range and flight endurance. This investigation indicates that the increase of the flight range and endurance due to wingspan extension influences on all selected speeds considerably. For instance, Fig. 15 represents the significant improvement of the range and endurance metrics for loitering velocities at 5,000 and 10,000ft. 


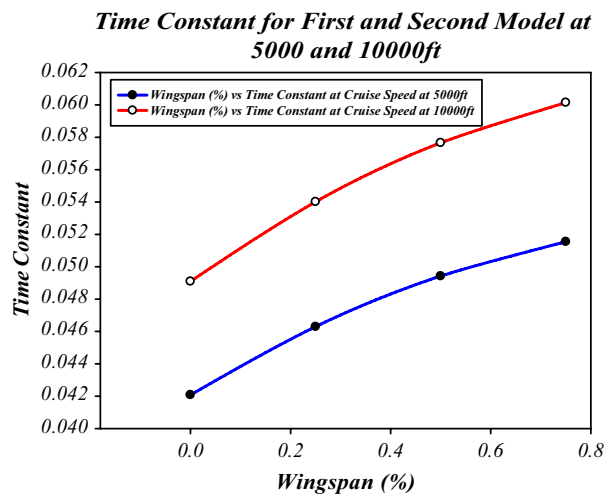

Figure 14. Time constant versus wingspan locations calculated for the first and second sweep angle model.
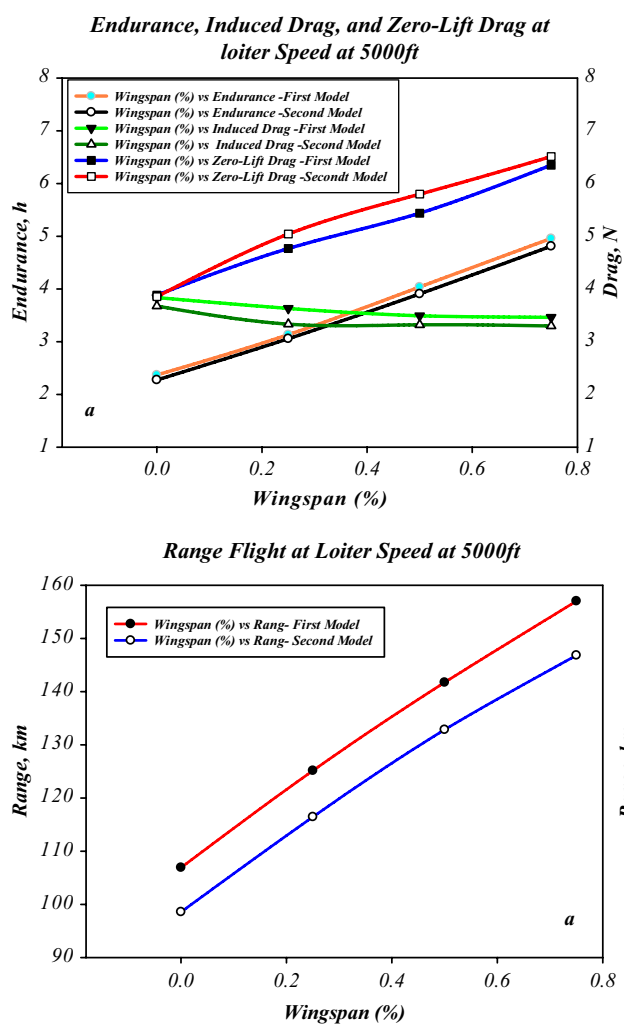
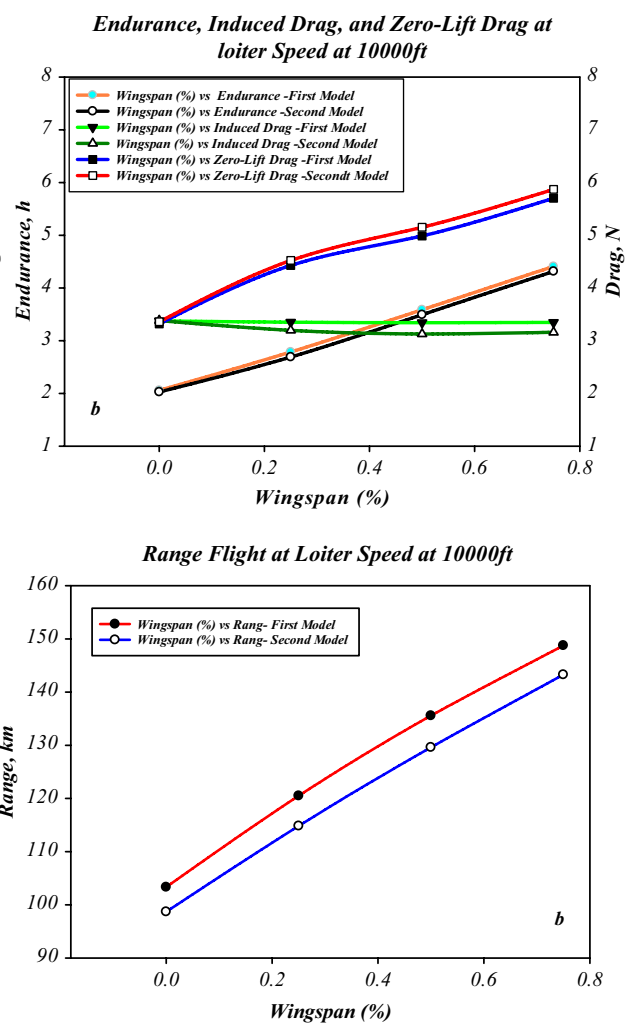

Figure 15. (a) Endurance and (b) range versus wingspan variation for first sweep angle model and second sweep angle model at loiter velocity.

The assessment of the increased endurance and range is based on the change of the $\frac{C_{L}}{C_{D}}$ and $\frac{C_{L}{ }^{3 / 2}}{C_{D}}$ ratios. The total drag computed for morphing wingspan is a combination of the induced drag and zero lift drag. As shown in Fig. 15, the wing span area of the wing has an important influence on the endurance and drag. Furthermore, Fig. 15 shows that the induced 
drag decreases when the wingspan extends, while the opposite occurs when the wingspan extends the zero lift drag increases. The maximum extension of the flight range to 5,000ft is up to $46.89 \%$ for the first sweep angle model and $43.16 \%$ for the second sweep angle model when the span extends from its original length to its full extension. The same pattern is found at the altitude of $10,000 \mathrm{ft}$, where the flight range is up to $43.94 \%$ for the first sweep angle model, and is up to $41.31 \%$ for the second sweep angle model. Therefore, the first sweep angle model improves the flight range at the altitude of 5,000ft by $8.64 \%$, and by $6.37 \%$ at the altitude of $10,000 \mathrm{ft}$ with respect to the second sweep angle model.

\subsection{CONCLUSIONS AND FUTURE WORK}

A variable morphing wingspan is an effective technology for enhancing aerodynamic efficiency and replacing conventional control surfaces. The improvement of flight performance leads to an increase in the flight range and endurance for a given flight. The purpose of this comparative study was to implement the analysis and the examination of three key characteristics using aerodynamics solver.

The major findings of this investigation resided in the fact that the variable span-morphing of the tapered wing can deliver the required improvements of performance because of the variation of wingspan extension, and sweep angle variation. However, estimated weight increases due to an equivalent stiffness of the structure and actuation system in comparison with the conventional wing. "In addition, flutter parameters (speed, damping) might change as they are sensitive to wingspan elasticity increase during the flight envelope. The aeroelastic parameters would also change depending on the motion of the moving segment (extension or retraction), and these changes should be taken into account in the wing design and optimisation process." The obtained results show the significant improvement in aerodynamic performance (for instance, at the cruise phase) by $32.39 \%$ for the first sweep angle model, and by $29.5 \%$ for the second sweep angle model. The rolling moment is sensitive to the lift distribution generated by span extension. The roll rate of variable wingspan decreases when the flight speed increases. The varying moment generated by variation of wingspan extension between the port and starboard wings suggests that the wing structures must be designed by taking into account the bending moment impacts at the wing root. The main advantages of variable morphing wingspan are the drag reduction; therefore, increase of range flight and endurance. The findings show that around $43.94 \%$ and $41.31 \%$ increase in flight range for the first and second sweep angle model can be achieved when the full wing extension is used.

Finally, it has been inferred that for future work, the best design shape of the variable morphing wing is the first sweep angle model. It is clear that for aerodynamic efficiency, the first sweep angle model is more efficient than the second sweep angle model for all speeds. For instance, at the cruise speed, the incremented ratio from the original position to $75 \%$ extension of its original length for the first and the second sweep angle models were of $32.39 \%$ and $29.5 \%$, respectively, which corresponded to the difference in the aerodynamic performance improvement between the two models of $9.34 \%$. However, the efficiency of the rolling moment reduces to $2.5 \%$. Regarding the range and endurance of flight, the first sweep angle model is $8.6 \%$ better than the second sweep angle model.

To accomplish the primary objective, several steps will be taken in future work. Additional analysis phases will be carried out for the stability and control derivatives. The variable tapered span-morphing wing structure and mechanism integration will be tested together. Numerical optimisation topology techniques will be generated to examine compliant adaptive wing structures for reducing the wing weight. 


\section{REFERENCES}

1. Ajaj, R., Bourchak, M. and Friswell, M. Span morphing using the GNAT spar for a mini-UAV: Designing and testing, Aircraft Structural Design Conference, 2014. p 16.

2. Murugan, S., Woods, B. and Friswell, M. Hierarchical modeling and optimization of camber morphing airfoil, Aerosp Sci Technol, 2015, 42, pp 31-38.

3. Pecora, R., Barbarino, S., Concilio, A., Lecce, L. and Russo, S. Design and functional test of a morphing high-lift device for a regional aircraft, J Intell Mater Syst Struct, 2011, 22, (10), pp 1005-1023.

4. Ajaj, R., Flores, E.S., Friswell, M., Allegri, G., Woods, B., Isikveren, A. and Dettmer, W. The zigzan wingbox for a span morphing wing, Aerosp Sci Technol, 2013, 28, (1), 364-375.

5. Della Vecchia, P., Corcione, S., Pecora, R., Nicolosi, F., Dimino, I. and Concilio, A. Design and integration sensitivity of a morphing trailing edge on a reference airfoil: The effect on high-altitude long-endurance aircraft performance, J Intell Mater Syst Struct, 2017, 28, (20), pp 2933-2946.

6. Tarabi, A., Ghasemloo, S. and Mani, M. Experimental investigation of a variable-span morphing wing model for an unmanned aerial vehicle, J Braz Soc Mech Sci Eng, 2016, 38, (7), pp 1833-1841.

7. Sofla, A., Meguid, S., Tan, K. and Yeo, W. Shape morphing of aircraft wing: Status and challenges, Mater Des, 2010, 31, (3), pp 1284-1292.

8. Barbarino, S., Bilgen, O., Ajaj, R.M., Friswell, M.I. and Inman, D.J. A review of morphing aircraft, J Intell Mater Syst Struct, 2011, 22, (9), pp 823-877.

9. Arena, M., Concilio, A. and Pecora, R. Aero-servo-elastic design of a morphing wing trailing edge system for enhanced cruise performance, Aerosp Sci Technol, 2019, 86, pp 215-235.

10. Concilio, A., Dimino, I., Ciminello, M., Pecora, R., Amoroso, F. and Magnifico, M. An adaptive trailing edge, Morphing Wing Technologies, 2018, Elsevier, pp 517-545.

11. Burdette, D.A., Kenway, G.K., Lyu, Z. and Martins, J. Aerostructural design optimization of an adaptive morphing trailing edge wing, 56th AIAA/ASCE/AHS/ASC Structures, Structural Dynamics, and Materials Conference, 2015, p 1129.

12. Cascio, M.L., Milazzo, A., Amendola, G., Arena, M. and Dimino, I. Optimization design process of a morphing winglet, Bioinspiration, Biomimetics, and Bioreplication VIII, Vol. 10593, 2018, p 1059305: International Society for Optics and Photonics.

13. Dimino, I., LeCCE, L. and PeCorA, R. Morphing wing technologies: Large commercial aircraft and civil helicopters, 2017, Butterworth-Heinemann.

14. Pecora, R., Amoroso, F. and Lecce, L. Effectiveness of wing twist morphing in roll control, $J$ Aircr, 2012, 49, (6), pp 1666-1674.

15. Gabor, O.Ş., Koreanschi, A. and Botez, R.M. A new non-linear vortex lattice method: Applications to wing aerodynamic optimizations, Chinese J Aeronaut, 2016, 29, (5), pp 1178-1195.

16. Gabor, O.Ş., Koreanschi, A., Botez, R.M., Mamou, M. and Mebarki, Y. Numerical simulation and wind tunnel tests investigation and validation of a morphing wing-tip demonstrator aerodynamic performance, Aerosp Sci Technol, 2016, 53, pp 136-153.

17. Koreanschi, A., Sugar-Gabor, O. and Botez, R.M. Drag optimisation of a wing equipped with a morphing upper surface, Aeronaut J, 2016, 120, (1225), pp 473-493.

18. Koreanschi, A., Sugar-Gabor, O. and Botez, R.M. Numerical and experimental validation of a morphed wing geometry using price-païdoussis wind tunnel testing, Aeronaut J, 120, (1227), pp 757-795.

19. Mestrinho, J., Gamboa, P. and Santos, P. 2011, Design optimization of a variable-span morphing wing for a small UAV, 52nd AIAA/ASME/ASCE/AHS/ASC Structures, Structural Dynamics and Materials Conference and in 19th AIAA/ASME/AHS Adaptive Structures Conference, p 2025.

20. Ajaj, R., Friswell, M., Saavedra Flores, E., Little, O. and Isikveren, A. Span morphing: a conceptual design study, 53rd AIAA/ASME/ASCE/AHS/ASC Structures, Structural Dynamics and Materials Conference and in 20th AIAA/ASME/AHS Adaptive Structures Conference, 2012, p 1510.

21. Beaverstock, C.S., Fincham, J., Friswell, M.I., Ajaj, R.M., De Breuker, R. and Werter, N. Effect of symmetric \& asymmetric span morphing on flight dynamics, AIAA Atmospheric Flight Mechanics Conference, 2014, p 545. 
22. Beaverstock, C.S., Woods, B.K.S., Fincham, J.H.S.-M. and Friswell, M.I. Performance comparison between optimised camber and span for a morphing wing, Aerospace, 2015, 2, (3), pp 524-554.

23. Vale, J., Leite, A., Lau, F. and Suleman, A. Aero-structural optimization and performance evaluation of a morphing wing with variable span and camber, J Intell Mater Syst Struct, 2011, 22, (10), pp 1057-1073.

24. WeIsShan, T.A. Morphing Aircraft Technology-New Shapes for Aircraft Design, Purdue University Lafayette, 2006.

25. Ivanco, T., Scott, R., Love, M., Zink, S. and Weisshaar, T. 2007, Validation of the Lockheed martin morphing concept with wind tunnel testing, 48th AIAA/ASME/ASCE/AHS/ASC Structures, Structural Dynamics, and Materials Conference, $\mathrm{p} 2235$.

26. Seigler, T.M. Dynamics and Control of Morphing Aircraft, Doctor of Philosophy, Virginia Tech University, 2005.

27. LI, W. and JIN, D. Flutter suppression and stability analysis for a variable-span wing via morphing technology, J Sound Vib, 2018, 412, pp 410-423.

28. GAO, B., KANG, R. and CHEN, Y. Deployable mechanism design for span morphing wing aircraft, Mechanism and Machine Science, Springer, 2017, pp 801-813.

29. Prakash, T. and Pant, R.S. Studies in telescopic span morphing of HALE UAV, 8th IEEE International Conference on Mechanical and Aerospace Engineering (ICMAE), 2017, pp 512-516.

30. McCormick, B. Aerodynamics Aeronautics and Flight Mechanics, New York, John Wiley \& Sons Inc., 1995.

31. Kevadiya, M. and Vaidya, H.A. 2D analysis of NACA 4412 airfoil, Int J Innov Res Sci Eng Technol, 2013, 2, 5.

32. Deperrois, A. XFLR5 - Analysis of foils and wings operating at low Reynolds numbers, Guidelines for XFLR5, 2009.

33. Traub, L.W., Botero, E., Waghela, R., Callahan, R. and Watson, A. Effect of taper ratio at low reynolds number, J Aircr, 2015, 52, (3), pp 734-747.

34. Liauzun, C. Aeroelastic response to gust using CFD techniques, ASME 2010 3rd Joint USEuropean Fluids Engineering Summer Meeting Collocated with 8th International Conference on Nanochannels, Microchannels, and Minichannels, 2010, pp 269-276. American Society of Mechanical Engineers.

35. Liauzun, C., Le Bihan, D., David, J.-M., Joly, D. and Paluch, B. Study of morphing winglet concepts aimed at improving load control and the aeroelastic behavior of civil transport aircraft, Aerospace Lab J, 2018, 14, pp 1-15.

36. LIaUzun, C. Assessment of CFD techniques for wind turbine aeroelasticity, ASME 2006 Pressure Vessels and Piping/ICPVT-11 Conference, 2006, pp 341-350. American Society of Mechanical Engineers.

37. Grisval, J.-P. and Liauzun, C. Application of the finite element method to aeroelasticity, Revue européenne des éléments finis, 1999, 8, (5-6), pp 553-579.

38. Langtry, R.B. and Menter, F.R. Correlation-based transition modeling for unstructured parallelized computational fluid dynamics codes, AIAA J, 2009, 47, (12), pp 2894-2906.

39. Coughtrie, A., Borman, D. and Sleigh, P. Effects of turbulence modelling on prediction of flow characteristics in a bench-scale anaerobic gas-lift digester, Bioresource Technol, 2013, 138, pp 297-306.

40. Ajaj, R.M., Friswell, M.I., Saavedra Flores, E.I., Keane, A., Isikveren, A.T., Allegri, G. and ADHIKARI, S. An integrated conceptual design study using span morphing technology, $J$ Intell Mater Syst Struct, 2014, 25, (8), pp 989-1008.

41. Nelson, R.C. Flight Stability and Automatic Control. New York, WCB/McGraw Hill, 1998.

42. Körpe, D.S., Çetin, K., Altınok, Morasata, R., Eren, B., Demircan, O.M., Kidane, B.S., Demir, O., Usama, M. and Kunnathur, N.S. "Design of a UAV with Variable-Span Morphing Wing, University of Turkish Aeronautical Association, 2016.

43. Kuttche, M.A.J. and Botez, R.M. Modeling novel methodologies for unmanned aerial systems-Applications to the UAS-S4 Ehecatl and the UAS-S45 Bálaam, Chinese J Aeronaut, 2019, 32, (1), pp 58-77.

44. TONDI, Y. and BoteZ, R. Semi-empirical estimation and experimental validation of the mass and the center of gravity location of the unmanned aerial system-UAS-S4 of hydra technologies, 
2016 International Conference on Unmanned Aircraft Systems (ICUAS), 2016, pp 1319-1326: IEEE.

45. Segui, M., Kuitche, M. and Botez, R.M. Longitudinal aerodynamic coefficients of hydra technologies UAS-S4 from geometrical data, AIAA Modeling and Simulation Technologies Conference, 2017, p 0579.

46. John, A.D. and Anderson, J. Introduction to Flight, McGraw-Hill, 1989.

47. Blondeau, J. and Pines, D. Pneumatic morphing aspect ratio wing, 45th AIAA/ASME/ASCE/ AHS/ASC Structures, Structural Dynamics \& Materials Conference, 2004, p 1808. 